\title{
Stress among the Working and Homemakers Women with Respect to Their Family Type
}

\author{
Muddanagouda Patil ${ }^{1 *}$
}

\section{ABSTRACT}

Women in modern global world have to play a dual role as homemaker and career builder. The present investigation was conducted to examine the stress among the working and homemaker women with respect to their family type. It was hypothesized that there is significant difference between the working women and homemakers of nuclear and joint family type. In order to verify the above hypothesis a sample of 90 women's were taken from Dharwad district, Karnataka State, India. Among them working women's were 45 (nuclear family N=23, joint family N=22) and homemakers were 45 (nuclear family $\mathrm{N}=22$, joint family $\mathrm{N}=23$ ). To measure the stress, the stress scale developed by Singh (2002) was administrated individually to the subjects. The data were subjected to ' $t$ ' analysis and the major findings of the study revealed that women from nuclear family experience significantly more stress than joint family women. And also the finding revealed that working women from nuclear family undergo significantly high stress than working women from the joint family. The finding also states that there is no significant difference between homemaker women belongs to joint or nuclear family.

Keywords: Stress, Working Women, Homemakers, Joint and Nuclear Family.

Nowa days everyone talks about stress. Not only just high pressure executives are its key victims but it also includes laborers, slum dwellers, working women's, businessmen, professionals and even children. Stress is a part of modern life, with increasing complexity of life, stress is likely to increase. Stress is built in the concept of role, which is conceived as the position a person occupies in a system.

The woman is placed in the difficult position of having to balance the multiple roles expected of her with the roles she wants to carry out for herself. For centuries, women's have been expected to fulfill the main role like as the sister, mother and wife, and this meant putting the family first before their own needs. Like family members and family system will be important in the women

\footnotetext{
${ }^{1}$ Research Scholar, Department of Psychology, Karnatak University, Dharwad, Karnataka, India *Responding Author

(C) 2016, M Patil; licensee IJIP. This is an Open Access Research distributed under the terms of the Creative Commons Attribution License (http://creativecommons.org/licenses/by/2.0), which permits unrestricted use, distribution, and reproduction in any Medium, provided the original work is properly cited.
} 


\section{Stress among the Working and Homemakers Women with Respect to Their Family Type}

for her life and career success. With the help of the husband, women's can find freedom and happiness and a happy woman is a happy wife and mother. Work and family are the two most important domains in a person's life and their interface has been the object of study for researchers world-wide. There is a felt need to balance and integrate family needs and career requirements (Sturges \& Guest, 2004) and research in the field of work family interface has increased dramatically in the past two decades (Frone, Yardley, \& Markel, 1997). A significant number of women believe that women must stay at home and place the family before themselves. If there are women who want to stay home instead of achieving success at the workforce, then it is their choice.

\section{What is Family?}

Family is considered to be the most essential part of a person's life. Every individual is taught about the importance of a family since their childhood days. Ford (1994) defined family as any living arrangement of two or more people who have child also. Now, there could be number of types of families that normally exist i.e. family may include single parent family, two parent family, extended family, step parent family etc. (Anderson, Burton \& Turner, 1993; Crowder \& Teachman, 2004; Ermisch \& Francesconi, 2001; Ford, 1994; Groman \& Braverman, 2008; Miller, 1997). With more liberties and choices for teens in life (Christensen, 2002) a family is more desperately in need to have a person who performs the guardian or care taker responsibilities which are necessary to be done to keep the teens tracked (Ford, 1994). However, this study describes nuclear family as a social unit composed of two parents and one or more children. On the other side, joint family system is describe as type of extended family composed of parents, their children, and the children's spouses and offspring in one household.

There are two types of family systems - joint family and nuclear family systems. Joint family is a type of extended family, which consists of parents, their children, spouses of the children and their offspring in one household. A nuclear family is composed of parents and their children.

\section{Joint family:}

A joint family gives closeness amongst the relations. People don't have a lonely feeling and there is always a support at the backend at times of need. The culture of crèche and day-boarding for the children, the tiny tots could be abolished in a joint family culture. People get to know the human values. Some characters of joint family are below drawn.

1. Dependency: As discussed, a joint family is an extended family and it consists of a lot of members. People can depend on each other for any kind of help. Thus, this is one of the best qualities that joint families possess.

2. Unity: Joint family creates an emotional bond between two generations and it helps to keep the family united in all the situations. The tradition and culture is passed on to the coming 


\section{Stress among the Working and Homemakers Women with Respect to Their Family Type}

generations so that they can take it forward. The proverb "United we stand, Divided we fall", goes true in the joint family system.

3. Preference of the youngsters: There are youngsters out there in the society, who prefer a social life with a better support system. These people believe in the system of joint family.

4. Provides an opportunity for leisure time: The joint family system provides an opportunity for leisure time as the female members divide the household work and finish it off very soon.

5. Social insurance: Joint family acts as a social insurance and a support for the widows and the old aged people. They are assured of a proper living.

\section{Nuclear family:}

A nuclear family is not all to blame. It has become the requirement of the era. People need to get shifted to earn their bread and butter. But everyone from the family going to different direction makes the joint family culture impossible. The children need to get adjusted to the boarding or the mothers need to sacrifice her career to take care of their children. The nuclear family gives privacy to the couples and they get enough time to spend together to strengthen their relationship. Some main characteristic of nuclear are below drown;

1. More freedom: Nuclear families have more freedom as compared to a joint family system. They do not have to worry about what the other members of the household may think. They can roam around freely and come back at any time without being answerable to anyone. Democracy exists in a nuclear family.

2. Bonding: Nuclear family is based upon the parental love and sibling connection. The mechanism of relationships in a nuclear family is very straight forward. It is based on the foundation of mutual respect and love for each other.

3. Kid's preference: Youngsters of a nuclear family prefer more freedom and less restriction. As both the parents go to work, kids may feel bored at home. They may prefer to go out and play with their friends or to go out for an outing. To carry out such activities, less restriction is essential.

4. Quarrels: Nuclear families face fewer quarrels when compared to a joint family. Usually, they are the small quarrels between a husband and wife or a child and the parents.

Either its Joint family or Nuclear Family everyone has their positive as well as negative part. In nuclear family you don't have to work according to others. You are your own boss. There are no foundations; you are free to live your life according to you. In joint family you have to work according to the family's situation, according to your elders or you can say you have to put each step very carefully so that your act should not hurt the sentiments of any other family members.

But apart from all these I will go in favor of joint family because in joint family you have support of your loved ones at your bad time. If something went wrong with us our elders are there to support, guide and help. Today whatsoever we are in society, it's because of them. If 
they hadn't scarifies their dreams to educate us and make us a good and successful human, we wouldn't be able to live a standard life today.

There is no doubt that generation gap has totally changed our mindset but again listening to our elders is not a that much deal for us because if we consider ourselves that much mature and intelligent, we must have the capability to convince them too if any of their point doesn't matches with your views.

But with the increase in urbanization, nuclear families are taking over the joint family systems. When compared to joint family, nuclear families many a times feel better. They provide a peace and calm environment at home as there are very few quarrels. Every individual after coming from work requires a peaceful atmosphere at home. As they say - "small family, happy family."

\section{LITERATURE REVIEW}

Bhattacharjeee, al. (1983) studied on family adjustment of married working and non-working women's. A specially developed adjustment inventory, a health-status questionnaire, a neuroticism scale, and an incomplete sentences blank to 76 married working and 70 married nonworking women's. No significant differences in adjustment or neuroticism were found between the working and nonworking nor were any differences found on the incomplete sentences measure of psychological conflicts. It is concluded that a woman's adjustment, whether employed or not, is a function of her own personality traits, expectations, and perceptions combined with those of her spouse and family members.

Sabre (2016) investigated the level of marital adjustment among women with reference to their type of family belonging to Madhya Pradesh. For the conduction of study a sample of 120 women (nuclear family=60 \& joint family=60) was purposively selected. The measure used for data collection was Pramod, K.; Kanchana, R. Marital Adjustment Scale. The data was analyzed by computing Means, SD, \& t-test. The results revealed that there was a significant difference in marital adjustment among women of nuclear and joint families. The women belonging to nuclear showed higher levels of marital adjustment as compared to women of joint families.

Patil (2016) studied on the stress among the working and non-working women's. It was hypothesized that the working women's has more stress than the non- working women's. In order to verify the above hypothesis a sample of 90 women's were taken. From which working women's ( $\mathrm{N}=45)$ and non-working women's $(\mathrm{N}=45)$. To measure the stress, the stress scale developed by Singh (2002) was administrated individually to the subjects. The data were subjected to ' $\mathrm{t}$ ' analysis and the major findings of the study reveals that the working women's has more stress than the non-working women's. 


\section{Stress among the Working and Homemakers Women with Respect to Their Family Type}

Reddy et, al. (2010) studied on work-life balance among married women employees. Family work conflict (FWC) and work-family conflict (WFC) are more likely to exert negative influences in the family domain, resulting in lower life satisfaction and greater internal conflict within the family. Studies have identified several variables that influence the level of WFC and FWC. Variables such as the size of family, the age of children, the work hours and the level of social support impact the experience of WFC and FWC. However, these variables have been conceptualized as antecedents of WFC and FWC; it is also important to consider the consequences these variables have on psychological distress and wellbeing of the working women.

Rattani (2012) studied on working and nonworking women's descriptions and experiences of their roles in society. A descriptive exploratory research design was used. After approval from ethics review committee, Aga Khan University, the data was gathered from women in three communities representing the low, middle and upper socioeconomic strata, in Karachi, Pakistan. The participants were selected by critical case sampling. The sampling was terminated once the saturation was achieved. The in-depth interviews were conducted by using the interview guide. Thirty-five women participated in the study. Data was analyzed using descriptive statistics. The findings showed that the participants identified three main roles of women in a society. These

roles are familial, financial supporter, and socio-political roles. Women's experiences and feelings related to these roles had an impact on their quality of life.

Shing (2014) studied on life satisfaction and stress among working and non-working women. A sample of 200 women (100 working \& 100 non-working) was drawn randomly from the population. Life Satisfaction Scale by Alam \& Srivastava (1996) and stress scale by Singh (2004) were used for data collection. Mean, standard deviation, , ${ }^{\text {te }}$ test and correlation were the statistics calculated. The results indicated that there was significant difference regarding life satisfaction and stress between working and non-working women. Results revealed that working and non-working women differed significantly on their life satisfaction $(t=5.52)$. Working women were more satisfied with their life, on stress scale non-working women have higher level stress as compared to working women. A significant negative relationship was found between life satisfaction and stress.

\section{Objectives:}

1. To find stress among working and homemakers belonging to nuclear and joint family type.

2. To find stress among working women belonging to nuclear and joint family type.

3. To find stress among home making women belonging to nuclear and joint family type.

\section{Hypotheses:}

1. There is a significant difference between working and homemakers belongs to nuclear and joint family type.

(C) The International Journal of Indian Psychology, ISSN 2348-5396 (e)| ISSN: 2349-3429 (p) | 118 
2. There is a significant difference between working women belongs to nuclear and joint family type.

3. There is a significant difference between home making women belongs to nuclear and joint family type.

\section{Sample:}

The study was conducted on 90 sample including 45 working and 45 homemaker women from Dharwad, Karnataka State, India.

\section{Tools:}

Stress Scale by Singh (2002) was used. This tool is self-report questionnaire with 40 items. There are 3 responses category - always, anytime, and not at all. Reliability coefficient of the scale was estimated by split half method and test retest method and correlation was found to be 0.82 and 0.79 respectively. Validity coefficient was computed with Bist Battery of stress scale (Abha Rani Bist) and correlation was found to be 0.61 .

\section{Scoring:}

Assign 2 marks for 'always', 1 mark for ' anytime' and 0 mark of 'not at all' sum up all the scores and interpret in terms of state of stress.

\section{Statistical Techniques:}

After scoring the data, the raw scores were converted into standard scores using 20.0 versions of SPSS, subsequently the mean and SD was calculated. The data was subjected to independent sample ' $t$ ' analysis to find the significant difference between the working and homemaker women in relation to their nuclear and joint type of family.

\section{RESULT AND DISCUSSION}

Table No 01: showing Mean, standard deviation and ' $t$ ' value of the nuclear and joint family women on stress.

\begin{tabular}{|l|l|l|l|}
\hline \multirow{2}{*}{ Stress } & \multicolumn{3}{|c|}{ Sample Group $(\mathbf{N}=\mathbf{9 0})$} \\
\cline { 2 - 4 } & Nuclear family women $(\mathbf{N}=\mathbf{4 5})$ & \multicolumn{1}{|c|}{ Joint family women $(\mathbf{N}=\mathbf{4 5})$} & 't' value \\
\hline Mean & 53.41 & 46.58 & \multirow{2}{*}{$3.43^{* * *}$} \\
\hline SD & 9.60 & 9.28 & \\
\hline
\end{tabular}

***= very high significant at 0.001 level.

The table no 01 shows means, standard deviation and ' $t$ ' value of the nuclear and joint type of family women on stress. The nuclear family women have more stress then joint family women's. The obtained mean scores are 53.41 and 46.58 respectively. The obtained standard deviations are 9.60 and 9.28 respectively. The obtained ' $t$ ' value is 3.43 . This result reveals that there is very

(C) The International Journal of Indian Psychology, ISSN 2348-5396 (e)| ISSN: 2349-3429 (p) | 119 
highly significant difference at 0.001 level between the nuclear and joint type of family women's on stress.

Table No 02: Showing Mean, Standard Deviation and ' $t$ ' value of working women from nuclear and joint family on stress.

\begin{tabular}{|l|l|l|c|}
\hline \multirow{2}{*}{ Stress } & \multicolumn{3}{|c|}{ Sample Group (N=45) } \\
\cline { 2 - 4 } & \multicolumn{1}{|c|}{ Nuclear family women's (N=23) } & Joint family women's (N=22) & $\begin{array}{c}\text { 't' } \\
\text { value }\end{array}$ \\
\hline Mean & 55.08 & 44.68 & \multirow{2}{*}{$4.07^{* * *}$} \\
\hline SD & 9.43 & 7.63 & \\
\hline
\end{tabular}

$* * *=$ very high significant at 0.001 level.

The table no 02 shows means, standard deviation and ' $\mathrm{t}$ ' value of the nuclear and joint family working women's on stress. The nuclear family working women's have more stress then joint family working women. The obtained mean scores are 55.08 and 44.68respectively. The obtained standard deviations are 9.43 and 7.63 respectively. The obtained ' $t$ ' value is 4.07 . This result reveals that there is very highly significant difference at 0.001 level between the nuclear and joint type of family working women's on stress.

Table No 03: Showing Mean, Standard Deviation and 't' value of homemakers women from nuclear and joint family stress.

\begin{tabular}{|l|l|l|l|}
\hline \multirow{2}{*}{ Stress } & \multicolumn{3}{|c|}{ Sample Group of House Holding Women's (N=45) } \\
\cline { 2 - 4 } & \multicolumn{1}{|c|}{$\begin{array}{c}\text { Nuclear family women's } \\
\text { (N=22) }\end{array}$} & Joint family women's (N=23) & 't' value \\
\hline Mean & 51.84 & 48.23 & 1.21 \\
\hline SD & 10.00 & 9.89 & \\
\hline
\end{tabular}

The table no 03 shows means, standard deviation and ' $t$ ' value of the nuclear and joint type of family homemaker women on stress. The homemaker women from nuclear family have more stress then joint family homemaker women. The obtained mean scores are 51.84 and 48.23 respectively. The obtained standard deviations are 10.00 and 9.89 respectively. The obtained ' $t$ ' value is 1.21 . This result reveals that there is no significant difference between the homemakers from joint and nuclear on stress.

\section{CONCLUSION}

1. There is very high significant difference between the nuclear and joint family women on stress. This result reveals that the nuclear family women's have more stress then joint family women.

(C) The International Journal of Indian Psychology, ISSN 2348-5396 (e)| ISSN: 2349-3429 (p) | 120 


\section{Stress among the Working and Homemakers Women with Respect to Their Family Type}

2. There is very high significant difference between the nuclear and joint family working womens on stress. This result reveals that the nuclear family working women have more stress then joint family works women.

3. On stress variable there is no significant difference between homemakers from the nuclear and joint family type, but nuclear family have more stress then joint family homemaker women.

\section{REFERENCES}

Bhattacharjee, Pratima, Bhatt, k. Kusum.1983. Family adjustment of married working and nonworking women's. Indian journal of clinical psychology.Vol.10 (2).497-501.

Ford, D. Y. (1994). An exploration of perceptions of alternative family structures among university students. Family Relations, 43(1), 68-73.

Kanchan Sabre (2016).Marital Adjustment among Women: A Comparative Study of Nuclear and Joint Families. The International Journal of Indian Psychology, Volume 3, Issue 2, No.5, DIP: 18.01.078/20160302 ISBN: 978-1-329-87724-5, January - March, 2016.

Muddanagouda Patil (2016). Stress Level of Working and Non-Working Women. The International Journal of Indian Psychology, Volume 3, Issue 2, No.4, Pp 31-37.

N. Krishna Reddy, M. N. Vranda, Atiq Ahmed, B. P. Nirmala, and B. Siddaramu. Work-Life Balance among Married Women Employees. Indian Journal of Psychological Medicine. 2010 Jul-Dec; 32(2): 112-118.

N. Krishna Reddy, M. N. Vranda, Atiq Ahmed, B. P. Nirmala, and B. Siddaramu (2010). WorkLife Balance among Married Women Employees. Indian Journal of Psychological Medicine. 2010 Jul-Dec; 32(2): 112-118.

Salma Amin Rattani (2012). Working and Nonworking Women's Descriptions and Experiences of their Roles in Society. International Journal of Humanities and Social Science Vol. 2 No. 19; November 2012, 230.

Shashi Kala Singh (2014). Life Satisfaction and Stress Level among Working and Non-Working Women. The International Journal of Indian Psychology: Volume: 01, Issue: 04, Pp 121128.

Stress scale developed and slandered by M. Singh (2002).

How to cite this article: M Patil (2016), Stress among the Working and Homemakers Women with Respect to Their Family Type, International Journal of Indian Psychology, Volume 3, Issue 4, No. 63, ISSN 2348-5396 (e), ISSN: 2349-3429 (p), DIP: 18.01.106/20160304, ISBN: 978-1365-32518-2 